\title{
POPPER'S MARXIST: PSEUDOSCIENCE AS POLICY PROBLEM
}

by

\author{
Aidan Hayes, \\ Bachelor of Arts \\ Dalhousie University, 2011 \\ Master of Arts \\ Queen's University, 2012
}

\author{
An MRP \\ presented to Ryerson University \\ in partial fulfillment of the \\ requirements for the degree of \\ Master of Arts \\ in the program of \\ Public Policy and Administration
}

Toronto, Ontario, Canada, 2019

(C)Aidan Hayes, 2019 


\begin{abstract}
AUTHOR'S DECLARATION FOR ELECTRONIC SUBMISSION OF A MRP
I hereby declare that I am the sole author of this MRP. This is a true copy of the MRP, including any required final revisions. I authorize Ryerson University to lend this MRP to other institutions or individuals for the purpose of scholarly research. I further authorize Ryerson University to reproduce this MRP by photocopying or by other means, in total or in part, at the request of other institutions or individuals for the purpose of scholarly research. I understand that my MRP may be made electronically available to the public.
\end{abstract}




\section{Popper's Marxist: Pseudoscience as Policy Problem}

Master of Arts (Public Policy and Administration), 2019

\section{Aidan Hayes, Department of Politics and Public Administration, Ryerson University}

Contemporary culture has seen an increase in the influence of fringe beliefs, chief among them pseudosciences: doctrines that masquerade as sciences. In light of the myriad ways in which the work of the public sector is intertwined with and depends upon that of scientists, it is essential that policymakers be able to recognize these pretender sciences. However, the academic literature has yet to yield a widely accepted and easily applicable definition of "pseudoscience". This paper proposes that pseudosciences are most adequately characterized by their origin in social contexts in which there is little open, critical discussion of ideas: hence, in contrast with genuine science, there can be no assumption by non-scientist observers that pseudosciences have withstood criticism prior to their promulgation as knowledge. The applicability of this proposal is demonstrated with a case study, where it is used to identify the pseudoscientific features of Andrew Wakefield's “anti-vaccine” advocacy. 


\section{Acknowledgements}

First and foremost, my thanks are due to my supervisor Dr. Michael McGregor and second reader Dr. Mitu Sengupta. Their supportive feedback and efforts to keep me on track are much appreciated - not to mention their willingness to take on a somewhat unorthodox project. At various points prior to the actual writing of this paper, Dr. Letitia Meynell, Mr. Tim Krahn, Dr. Andrew Fenton, Dr. Alana Cattapan, and Dr. Mélanie Frappier did much to help refine the ideas expressed within. Without their-minded criticism, I would have known neither precisely what I wanted to say, nor how best to say it.

Finally, many thanks to Lily McCall, for supporting my decision to pursue graduate study, and for offering much-needed encouragement at times when completing this project seemed like an insurmountable task. 


\section{Table of Contents}

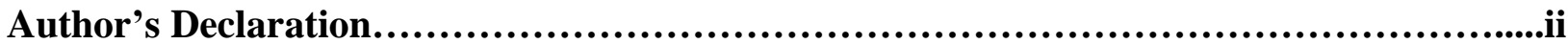

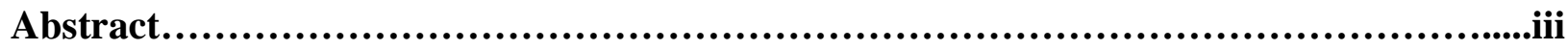

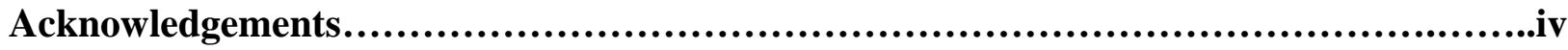

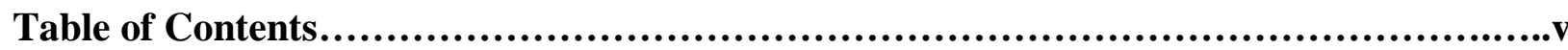

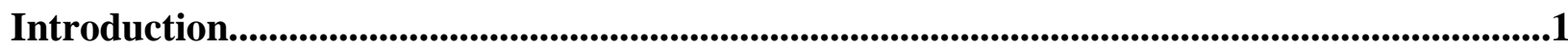

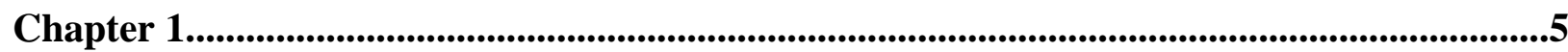

Chapter 2...........................................................................................................................................................17

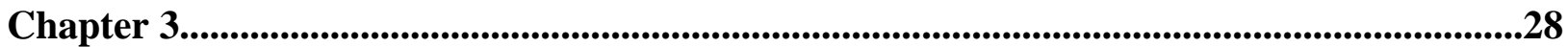

Chapter 4 ......................................................................................................................................................44

Conclusion.............................................................................................................................................................55

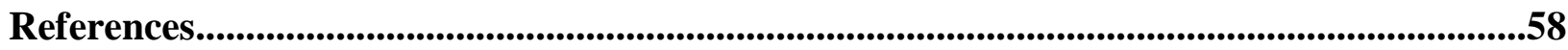




\section{Introduction}

Among scientists, it is common sense that both phrenology and astrology are pseudosciences. However, it is not clear what common property justifies their inclusion in a single pejorative category. This uneasy mix of vagueness and intuitiveness evokes United States Supreme Court Justice Potter's celebrated remark that while he could not give a precise definition of "hard-core pornography", he "kn[e]w it when I see it" (Gewirtz, 1996, p. 1023). An offshoot of efforts to identify the essential characteristics of science itself (often known as the "problem of demarcation"), the difficulty of defining pseudoscience has long attracted the attention of philosophers of science. Unlike the subjects of many long-running philosophy disputes, it has recently attained a new prominence. With world leaders such as Indian Prime Minister Narendra Modi mortifying scientists by claiming that interspecies surgical head transplants were possible in the distant past (Kumar, 2019), and surveys finding rapid growth in the percentage of Americans who believe in alien visitation and the existence of a lost city of Atlantis (Chapman University, 2018), pseudoscience has become a distinctively contemporary social issue.

Here, I consider pseudoscience as a problem for both public policy and academia. Resolving the longstanding debate over demarcation is pertinent for two reasons. First, science is not itself an isolated policy field, but rather is intertwined with the business of governance across a range of sectors in which the threats posed by pseudoscience may manifest quite differently. Understanding exactly what we mean when we call something "pseudoscientific" is necessary simply to ascertain what counts as an instance of the problem at hand. Second, isolating the universal features of pseudoscience is essential not only for identification of individual cases, but for furthering understanding of the phenomenon itself. In the long term, the most effective way 
to prevent pseudoscience from gaining adherents is a science-literate population, and so better comprehension can aid in devising public education strategies for countering pseudoscientific beliefs among citizens.

To this end, the paper proposes a reevaluation of one of the most widely-read (and criticised) criteria of demarcation; Karl Popper's doctrine of falsifiability. According to Popper $(1959 ; 2002)$, legitimate science is distinguished by the fact that it is susceptible to testing. Genuinely scientific theories make predictions, which can be weighed against evidence via observation and experimentation. Whether or not a prediction is successful is not always cut and dry; successful predictions are sometimes later shown to be coincidental, while failed ones may be the result of measurement error. In the wake of a disputed prediction, scientific procedures can be refined, by qualifying hypotheses or refining procedures. Consequently, the fact that scientific theories ${ }^{1}$ involve tests makes them amenable to argument, and via argument to improvement over time. Criticism in science, in other words, is constructive criticism.

I argue that Popper's proposal can be defended against its many critics ${ }^{2}$ if falsifiability is reinterpreted. Generally, it is understood as something akin to a grammatical property of individual sentences. Thus, the falsifiability of a scientific theory depends on the sorts of statements which can be inferred from it. I suggest that falsifiability provides for a better criterion of demarcation if defined a property of the standards of discourse within communities of practice: a social more that is facilitated by the way people interact with one another, rather than a feature of particular sentences or areas of inquiry. On this reading, "falsifiability" is a matter of whether or not criticisms will, empirically speaking, receive a fair hearing among those

1 Throughout this paper, I follow the literature in using "theory" non-literally, to describe in general the outputs of scientific research. I do not intend to suggest that only theories can be evaluated as pseudoscientific.

2 To be described in Chapter 1 below. 
who advocate for a theory or conduct research within a field: the "community of practice" associated with a possible pseudoscience. Here, the paper draws on Helen Longino's work on scientific objectivity, proposing the following definition of pseudoscience:

A theory, practice, belief, or research program is pseudoscientific if, and only if,

(1) It purports, tacitly or explicitly, to enjoy the authority typically associated with science, and

(2) It has emerged from, or circulates within, a community within which it is not subject to critique, and hence is not apt to be falsified.

On the account proposed, pseudoscience is differentiated from science on the grounds of credibility and trustworthiness, standards of interpersonal exchange, which are in turn conferred by the social contexts within which these activities take place. Pseudoscience does not simply generate falsehoods where science generates truths, or investigate unserious subjects where science investigates serious ones. As Longino has argued convincingly, there are reasons to interpret scientific findings as good-faith attempts to establish credible explanations of empirical phenomena. To say that scientists can be trusted is not to say that they are never wrong, but rather that scientific statements are generally plausible products of concerted truth-seeking activity, and not deceitful, arbitrary, or nonsensical.

As I shall argue, this trust is warranted because science is conducted within contexts that are (albeit imperfectly) conducive to critical examination of ideas. Regardless of however palatable or scrupulous the characters of scientists might be, they operate within institutions in which there is an established expectation that one will tolerate others' questioning of their work ${ }^{3}$. Given this expectation, scientists who are unwilling to take rival theories or questions about their

3 In some cases, such as the process of publication, this may even be mandated. 
data seriously or otherwise demonstrate a lack of accountability to their ideas may well experience difficulty advancing their careers. Thus, they operate within structures which incentivize responsiveness to critique. In contrast, the pseudoscientist does not practice in spheres where they are encouraged to answer constructive critique ${ }^{4}$. The non-scholarly press does not practice rigorous peer review, nor do the crowds at anti-vaccine rallies ask difficult questions of their fellows. Hence, to assume that utterances outside a context conducive to critical discourse are made in the pursuit of knowledge is unwarranted; there are too many rival incentives which may be felt. In short, to deem something as pseudoscientific is not tantamount to declaring it false, but to caution that it should not be trusted ${ }^{5}$.

The first section to follow will elaborate upon the central issues outlined above: the problem that spurious science poses from a policy perspective, and the inability of theorists to conceptualize it adequately. The second will conduct a review of existing literature on the topic, illustrating the impasse that has been reached and the many difficulties in arriving at an adequate criterion of demarcation. The third section will introduce the paper's reinterpretation of Popper's work on falsification, defending the proposed conceptualization of pseudoscience offered above. The fourth section will, in turn, operationalize this understanding, illustrating with reference to Andrew Wakefield's notorious study of vaccination as a cause of autism spectrum disorders the "symptoms" that pseudoscientific research tends to exhibit. Finally, the fifth section will conclude with a discussion of the advantages and implications of adopting the proposed definition of pseudoscience.

4 Here it is important to note that not all responses to criticism are answers that acknowledge their merit. 5 Astute readers will notice an asymmetry here: science is trustworthy, whereas pseudoscience is defined by its untrustworthiness. This is addressed in Chapter 3 below. 


\section{Chapter 1}

In this chapter, I make the case that pseudoscience represents not merely a scholarly curiosity, but a social problem that demands a response from institutions such as government. First, I review briefly the interdependence of state and science, to illustrate that the former depends meaningfully upon the latter. Second, I explain what this paper considers to construe "pseudoscience": generally, an increasing tendency for groups and individuals alike to reject mainstream scientific authority over matters of interest, such as physical health, in favour of extravagant claims and research programs that assert themselves to be science. Third, having shown that pseudoscience is a problem, I argue that the academic literature on the subject, while considerable and insightful, has yet to yield the means by which we might understand what pseudoscience really is, or why it should be treated with skepticism. In later chapters, I take up this challenge.

The business of the modern state is thoroughly intertwined with the practice of science, with which policymakers in the civil service and the broader public sector interact in at least four important ways. First, state-run departments and agencies fund scientific research. In Canada, governments fund science most obviously through their subsidies for teaching hospitals and research universities, but also through funding agencies such as the Natural Sciences and Engineering Research Council, Canadian Institutes of Health Research, Defence Research and Development Canada, and the Social Sciences and Humanities Research Council. Second, education at all levels is generally state-funded. Hence government has a hand in both the training of professional scientists at universities and the science education received by the lay public at primary and secondary schools. Third, governments rely on scientific evidence in order to guide policy decisions. Health spending, for example, is allocated in part on the basis what 
research identifies as priorities, whether curative or preventative interventions are more effective, and so on. Fourth, after determining a course of action, governments also employ science when enacting these policy choices. Efforts to decide on or enforce a price on carbon emissions, for instance, would be impossible without scientific measurement of emissions themselves and their concentration in the atmosphere.

Consequently, it is essential that policymakers have at their disposal the necessary tools to distinguish credible research from that which falls short of scientific standards. All four ways in which governance intersects with science are dependent on that science's reliability. After all, funding of bad science is wasteful, education in bad science leaves citizens in ignorance, policies premised on bad science are likely to be poor choices, and policies implemented with the aid of bad science are likely to fail. Fortunately, it will, in most cases, suffice to resort to Justice Potter's aforementioned stratagem, and trust in intuition to distinguish proper from improper claimants to the status of science. In general, most reasonably-well educated citizens know science when they see it. An analyst in the employ of the government may not be able to define "science", or to interpret the results of empirical research relevant to policy priorities. Instead, they are assumed able to recognize those who do possess sufficient understanding of the relevant science, so that those crafting policy can draw upon this expertise.

Unfortunately, the reality is not so convenient. It has long since become a cliché to note that the current climate is one of excess skepticism of "experts" at best, and widespread irrationality at worst. Reputable opinion polling has found that as many as one American in twenty-five believes that shape-shifting reptiles wielded political power in modern society ${ }^{6}$,

6 Public Policy Polling, "Republicans and Democrats differ on conspiracy theory beliefs," accessed May 26, 2019, https://www.publicpolicypolling.com/wp-content/uploads/2017/09/PPP_Release_ National_ConspiracyTheories_ 040213.pdf. 
while more than one in three believes in the recent presence of extraterrestrials on Earth and over half believe in hauntings ${ }^{7}$. The proportion to believe in the latter two scenarios has grown by double digits in two years, suggesting that these fringe beliefs are actually becoming more prevalent. Meanwhile, the fringe movements of decades past have proven their longevity. AIDS denialism, according to which HIV is a harmless virus that merely tends to correlate with immune-system collapse caused by substance abuse, toxicity (of antiretroviral drugs), or malnutrition, has persisted past its 1980s heyday, attracting the devotion of numerous activists ${ }^{8}$.

Fringe beliefs take many forms, including conspiratorial, occult, or otherwise fantastical explanations for social, environmental, and medical phenomenon, and for reasons that are outside the scope of this paper, it appears that their mass appeal is growing. Of particular interest here are those often described with the pejorative term "pseudoscience". Typically, it is applied to theories, claims, and research programs which proponents claim are scientific ${ }^{9}$ (or in some cases, a superior alternative), but which the majority of scientists consider to fall short in terms of truthfulness or methodological rigour. Take, as a classic example, so-called Young Earth "Creation Science", according to which an honest reckoning with the available geological, hydrologic, and fossil evidence would reveal it to be best explained by spontaneous creation of the Earth approximately six thousand years in the past.

The myriad pseudosciences often appear ridiculous or even comical. Nonetheless, I hold that they should be taken seriously, as a genuine threat not only to the knowledge-seeking mission of science and academia more broadly, but to public safety. In the winter of 2019, the

7 Chapman University, "Survey of American Fears 2018: Paranormal", October 16, 2018, https://blogs.chapman.edu/wilkinson/2018/10/16/paranormal-america-2018/ 8 Seth Kalichman, Denying AIDS: Conspiracy Theories, Pseudoscience, and Human Tragedy (New York, NY: Springer, 2009).

9 In some cases, this claim is implicit. 
news media reported that one Quebec-based charity had plans to spend $\$ 350000$ sending homeopaths to 'treat' life-threatening disease in Honduras ${ }^{10}$. To make matters worse, this was taxpayer money, received from the federal government. In a less dangerous but more profligate case, one group of researchers in the United Kingdom found that the National Health Service had spent approximately $\$ 1.3$ million CAD training staff with the use of neuro-linguistic programming (NLP) ${ }^{11}$. Based on the tailoring of communication strategies to supposed intrinsic and subconscious preferences of individuals for particular tropes in diction and imagery, NLP is essentially an ineffectual form of hypnotism, with no solid scientific evidence for its efficacy ${ }^{12}$. Clearly, there are cases where pseudoscience is able to obstruct the work of the public sector. Here at least three features set it apart from the rest of the fringe. First, adherents of other fringe movements often promote their beliefs and practices in areas that are simply not of interest to most people. Those claiming to possess mystical powers of fortune-telling, or to have been mandated to spread the message of universal peace and love across the Earth by extraterrestrials, have a limited audience simply by virtue of their subject matter. Pseudoscience, in contrast, tends to compete with "mainstream" science as a source of information concerning important matters (especially in health care), as the examples above illustrate. Moreover, it often counsels the outright rejection of "establishment" science in areas that inform everyday life. For instance, the "anti-vaxx" movement asserts that vaccines are dangerous, and that doctors and pharmaceutical companies conspire with ill intent to promote their uptake. Research shows that populations with

10 Vik Adhopia, "Why is $\$ 350000$ in Canadian Aid Being Used to Send Homeopaths to Honduras?”, CBC News, February 23, 2019, https://www.cbc.ca/news/health/federal-aid-homeopaths-honduras-1.5030384.

11 Jackie Sturt, Saima Ali, Wendy Robertson, David Metcalfe, Amy Grove, Claire Bourne and Chris Bridle, "Neurolinguistic Programming: A Systematic Review of the Effects on Health Outcomes," British Journal of General Practice 62, no. 604 (2012): 758. DOI: 10.3399/bjgp12X658287.

12 Ibid. 
greater exposure to anti-vaxx media exhibit diminished vaccination rates ${ }^{13}$. Meanwhile, infectious diseases such as measles, once thought to be on the road to elimination, are returning to prominence, and implicated among other causes is this growing prevalence of "vaccine hesitancy"14.

Second, apart from the topics that engage them, the pseudoscientific subset of fringe practitioners poses a threat precisely because they aspire to attain the authority of scientists. This encourages them to engage in lobbying and advising on matters of public life, posing as sources of knowledge with regard to their chosen field (see the aforementioned anti-vaxx movement). This is one means by which pseudoscientists may perform their pantomime of "expertise"; moreover, acquiring influence over public life a likely motive for practicing pseudoscience ${ }^{15}$. One recent study investigated the International Life Sciences Institute (ILSI), a global organization and registered charity. ILSI, which receives funding from a number of large corporate sponsors, claims to provide the public sector with neutral scientific advice and researchers with funding ${ }^{16}$. Its official website describing its mission as "provid[ing] science that improves human health and well-being and safeguards the environment" ${ }^{\prime 17}$, and several operating

13 Anna Kata, "Anti-vaccine activists, Web 2.0, and the postmodern paradigm: An overview of tactics and tropes used online by the anti-vaccination movement," Vaccine 30, no. 25 (2012): 3779. doi:10.1016/j.vaccine.2011.11.112 14 Sophie Cousins, "Measles: A Global Resurgence," The Lancet Infectious Diseases 19, no. 4 (2019): 363. https://doi.org/10.1016/S1473-3099(19)30129-X

15 The incentive for this aspiration may vary considerably. Indeed, I think it is likely that some pseudoscientists are true believers who genuinely consider themselves to be on a mission to enlighten the masses, others are mere hucksters with financial motives, and still more simply seek validation through commanding an audience. Hence, I assume no universal motive beyond the acquisition of authority, which itself can be valued for any number of reasons.

$16 \mathrm{I}$ am aware that, while industry-funded research is often viewed with skepticism, it is not usually described as "pseudoscience" (although Steel et al. do, in fact, invoke the term briefly). I address this matter toward the end of Chapter 3, and again in Chapter 4.

17 International Life Sciences Institute, “Mission \& Operating Principles”, accessed July 132019 , https://ilsi.org/about/mission/. 
principles mandate ILSI to refrain from advocacy, dispensing research funding only to work for the public good.

However, a review of correspondence between ILSI and its funders revealed, among other things, the latter offering congratulations for determining in advance the results to be found by ILSI studies - namely, results 'debunking' the need for public health programs ${ }^{18}$. Other email chains cited by Steel et al. find senior ILSI figures and their affiliates soliciting advice from stakeholders as to the best means of "strategically" making connections within the World Health Organization (WHO), and describing a scenario in which ILSI's "opponents" "win" the battle for public opinion, while "we all lose"19. Perhaps most alarmingly, the latter remark was made by an academic collaborator. Another e-mail finds ILSI founder and former president (and former vicepresident of the Coca-Cola corporation) Alex Malaspina bemoaning a lack of "dialogue" with the head of the WHO, stating that "This threat to our business is serious" ${ }^{20}$ (emphasis original). Plainly, to be perceived as embodying the combination of expertise and impartiality associated with science is valuable, and can be deployed to enable the pursuit of interest that do not align with society as a whole.

Third, while the beliefs of pseudoscientists may be on the fringe, they themselves may occupy positions of prestige and influence. Writing of the continued flourishing of AIDS denialism, Seth Kalichman describes it as "traceable to one man": the rogue scientist Peter Duesberg $^{21}$. With a doctorate in chemistry and professorship in molecular and cell biology, Duesberg spent the 1970s and the first half of the 1980s as a distinguished researcher at the

18 Sarah Steel, Gary Ruskin, Lejla Sarcevic, Martin McKee \& David Stuckler, “Are Industry-Funded Charities Promoting "Advocacy-Led Studies" or "Evidence-Based Studies"?: A Case Study of the International Life Sciences Institute. Globalization and Health 15 no. 36 (2019): 3. https://doi.org/10.1186/s12992-019-0478-6. 19 Ibid., 5.

20 Ibid., 6.

21 Kalichman, Denying AIDS, 25 
forefront of what might be called 'establishment' cancer research. He was hailed for his work in explicating the genetic basis of some cancers; Deusberg's crowning achievement was the discovery of src, a gene of viral origin that can cause leukemia ${ }^{22}$. At some point during the 1980s, Deusberg abandoned his genetic cancer studies (abruptly, it appears), adopting in their stead the view that no cancers have a genetic or viral basis. Rather, the proximal cause of cancer is aneuploidy, or the survival of cells which have been left with usually-fatal chromosomal abnormalities and instead replicated uncontrollably ${ }^{23}$. Aneuploidy, in turn, is attributable to environmental causes such as drug abuse and pollution, rather than any inherent personal characteristic. Subsequent to this unusual turn, Deusberg began to argue that HIV, much like the viruses he once held to be a cause of leukemia, was merely coincident to AIDS. In its place, he asserted, environmentally-caused chromosomal disorders were responsible ${ }^{24}$.

This, as Kalichman shows, is a wildly implausible view, as no environmental cause correlates with AIDS symptoms the way that HIV infection does, while there are countless cases of successful treatment with antiviral drugs ${ }^{25}$. It is perhaps attributable to the fact that Duesberg has no actual experience studying HIV/AIDS: a fact which has not deterred him from attributing his inability to secure research funding to bias in the peer review process ${ }^{26}$. Both Duesberg's scientific positions and his claims of conspiracy in the world of science funding have attracted a coterie of fervent supporters. Many are practicing scientists, academics in other fields, or professional journalists ${ }^{27}$, and thus empowered both to occupy a publicly-visible platform and to speak with the appearance of credibility. Consequently, Duesberg and several other like-minded

22 Ibid., 27.

23 Ibid., 29.

24 Ibid., 31.

25 Ibid., 42-43.

26 Ibid., 51.

27 Ibid., 53. 
individuals were appointed to a state AIDS advisory panel by former South African President Thabo Mbeki, preceding a period in which the nation's health minister promoted vitamins as a treatment for AIDS, while claiming that antiretroviral drugs were toxic ${ }^{2829}$.

It is thus evident not merely that pseudoscientific creeds can be dangerous, but that their proponents have demonstrated both the desire and the capacity to influence public affairs. As illustrated above, actors in the field of public policy are not typically experts in a given field of knowledge, but generalists whose principle skills lie in the synthesis and translation into practice of knowledge produced by others, including scientists. Therefore, I hold that the public problem of pseudoscience lies in the following conundrum. Policymakers must be able to identify (and avoid) pseudoscientists and their work. However, they must do this without having extensive knowledge of the relevant subject area (for instance, virology), and without being able to assume that pseudoscientists can be identified by obvious traits such as a lack of formal credentials. In other words, when faced with competing claims to expert knowledge of a given area, they must be able to recognize which is the genuine authority and which is the Duesberg.

Among the tools necessary for policymakers to recognize examples of pseudoscience must be an understanding of the concept; a definition that is precise enough to minimize marginal cases and lend itself to ready operationalization, or in other words, a solution to the demarcation problem. Reliance on intuition rather than clear-cut understanding will not suffice to distinguish legitimate from illegitimate science when pseudoscientists share the superficial trappings of respectability enough to command professorships and attract research funding. Unfortunately, the existing literature does not provide any especially promising candidates.

28 Ibid, 130.

29 Mbeki's successor, perhaps echoing this attitude, once testifying during his own trial for rape that he relied on post-coital showers rather than condoms to avoid HIV infection. "SA's Zuma 'Showered to Avoid HIV'," BBC World News, April 5, 2006. http://news.bbc.co.uk/2/hi/africa/4879822.stm. 
Demarcation has attracted the attention of many influential figures in the philosophy of science, but despite a record of publications dating at least to Popper's 1934 book Logik der Forschung (which coined the phrase "demarcation problem"; unpublished in English until its 1959 translation as The Logic of Scientific Discovery), no scholarly consensus has emerged. Moreover, there has not even been any significant consolidation of expert opinion. For the most part, each writer on the topic espouses a theory seconded by few if any others.

Perhaps the nearest thing to a central dispute is not between adherents to different candidate criteria of demarcation. Rather, it is the debate over whether or not demarcation is even possible. The historian of science Michael D. Gordin has argued that it is not. Gordin understands "pseudoscience" in much the same way others do: a term that denotes unwarranted claims to the status of science, and consequently one that serves only as an insult, and never as a self-identification. Pseudoscientists are not merely practicing science incompetently, but are outright pretenders or "mimics" 30 . They reside entirely "off the grid" that typologizes the sciences, but they strive to be included ${ }^{31}$. He holds that this mimicry explains why it has been so difficult for scientists or sympathetic philosophers to invent a doctrine of demarcation that encapsulates the essence of pseudoscience. There is no such essence, and each such proposal simply invites further adaptive mimicry. Hence, as Gordin sees it, the real question with regard to pseudoscience is what it "Does, not means" ${ }^{32}$. It cordons off that which scientists (in a purely descriptive rather than normative sense) consider to be unacceptable, but in doing so herds

30 Michael D. Gordin, The Pseudo-Science Wars: Immanuel Velikovsky and the Birth of the Modern Fringe (Chicago, IL: University of Chicago, 2013).

31 Ibid., 1.

32 Ibid. 
together a hodgepodge of theories, practices, and persons "with very little in common...besides being hated by assorted scientists" ${ }^{\prime 3}$.

Larry Laudan, who reaches similar conclusions, argues that the history of demarcation efforts has forced a retreat away from the concern that actually matters: the attainment of wellfounded beliefs. He notes that it was long taken for granted that Aristotle had successfully delineated the boundaries of scientific knowledge. Aristotle held that science was distinguished from opinion on the basis of its certainty, and from craft or technical knowledge by its emphasis on explanation from first principles ${ }^{34}$; thus, it asks "why", rather than "how", and contents itself only with certain answers ${ }^{35}$. The explanatory criterion fell first, when the astronomers of the 17 th century contented themselves with successful predictions of the movement of heavenly bodies, claiming no understanding of why bodies were seen to move in a given way. While the insistence on certainty lasted longer, it too was abandoned during the 19th century, with the embrace of "fallibilist" conceptions of knowledge ${ }^{36}$. Consequently, those interested in demarcation turned from standards of knowledge to standards of methodology, attempting to show that the hallmark of science was a distinction (and laudable) set of rules for practice. However, given the diversity of what was known as "science" by this point, it proved impossible to describe a single, idealized scientific method that bore any close relation to practice.

Hence, demarcation efforts changed course again, adopting what Laudan refers to as "syntactic and semantic strategies" 37 and taking up an overriding concern with the form of claims made on behalf of scientific theories. This latter shift, however, came at considerable cost.

33 Ibid, 2.

34 This distinction is echoed today in that between "natural" (or "pure") and "applied" sciences.

35 Larry Laudan, Beyond Positivism and Relativism (Boulder, CO: Westview Press, 1994), 211-212.

36 Ibid., 212-213.

37 Ibid., 219. 
Demonstrably false theories could now pass as scientific, so long as they could be expressed in terms that fit the prescribed format. Laudan regards this as self-evidently absurd, given that the presumptive significance of the entire scientific endeavour, and consequently that of efforts at demarcation, is that it can help show the way to well-founded beliefs. Thus, he concludes that demarcation is a "pseudo-problem", neither admitting nor in need of a solution ${ }^{38}$. Our concern should therefore be entirely with the demarcation between well- and poorly-founded belief, with ““pseudo-science' and 'unscientific'...just hollow phrases which do only emotive work for us" ${ }^{\text {"39 }}$.

In at least one critical respect, Laudan is certainly correct. What matters for the crafting of good policy is well-founded information about the outside world. Whether that information comes from sources of expertise 'worthy' of the name 'science' holds precisely no import so long as it is likely to be true. However, this is not quite enough to make demarcation a pseudoproblem. Laudan wavers between references to demarcating science from non-science, and science from pseudoscience (see, for instance, the quote at the end of the preceding paragraph). He treats both distinctions as a single question, but it is the former and not the latter distinction between science and non-science that he has shown to be unimportant. To call something 'nonscientific' is not in all contexts an insult. History, for example, is not a science, and yet it serves as an important source of knowledge. To call something "pseudoscientific", on the other hand, is always an insult.

As Gordin notes, this is tantamount to an allegation of dishonesty, of false pretense, or at best, self-promoting delusion. Whatever science is, the fact remains that those things we are accustomed to thinking of as 'scientific' enjoy great prestige. As Laudan himself puts it, “"scientific experts' play a privileged role in many of our institutions...If scientists say that

38 Ibid., 221.

39 Ibid., 222. 
continents move or that the universe is billions of years old, we generally believe them, however counter-intuitive and implausible their claims might appear to be" ${ }^{\prime 40}$. In other words, to have one's practice recognized as 'science' enables one's exercise of power. Consequently, it matters what is recognized as such. Unlike historians, the purveyors of pseudoscience are eager to gain this recognition. Therefore, I adopt here a neutral position with regard to the positive question "What is science?". I do not pretend to know, and it is my aim that the account which follows is compatible with any likely demarcation of science from non-science. The true demarcation problem, as I see it, is between science and pseudoscience, and so my concern is with identifying disqualifying features, not qualifying ones. Therefore, the position I will take throughout the rest of this paper is that it is irrelevant whether or not a pseudoscience could, in the absence of its pseudoscientific features, count as a science.

40 Ibid., 210. 


\section{Chapter 2}

As discussed above, the extent literature on pseudoscience has thus far been unable to provide policymakers with a demarcation criterion (or criteria) suited to the necessary work: excluding dishonest or factually suspect research from receiving public support in the form of funding or endorsement in the classroom, and from informing decisions intended to be made in the public interest. The review that follows will survey an assortment of works addressing the conceptual problem that is pseudoscience, principally in the Anglo-American tradition in the philosophy of science. It will not attempt to decisively refute individual proposals for demarcation criteria on grounds such as conceptual coherence, empirical adequacy, or pragmatic applicability. Indeed, to give a fair enough hearing to justify attempting to refute a body of work the size of the extant literature on pseudoscience would be implausible. Given this, I see two justifications for introducing yet another attempt at demarcation. First, scholars have yet to "converge" on any existing proposal; it is rare for publications in this area to endorse or defend existing criteria of demarcation. Second, authors such as Laudan and Gordin have indicated dissatisfaction with the project of demarcation in its own right. Taken together, these facts indicate that there are contributions yet to be made to the literature as a whole. Thus, in this review, my aim is relatively modest: to make note of both the strengths and the faults of previous scholarly efforts. At the conclusion of the chapter, this will inform an account of the obstacles a successful criterion would have to surmount.

\subsection{Pseudoscience as attitude}

Philip Kitcher has expressed concerns with the common habit of making reference to pseudoscience, as opposed to pseudoscientists. Use of the former term as pejorative of choice carries the implication that it is the activity or the doctrine it itself which is problematic. In turn, 
this suggests that certain fields of study are what is "unfit". This worries Kitcher. He notes that many of the theories on today's pseudoscientific fringe, such as the role of a divine creator in natural evolution, were once widely accepted by figures such as Newton and Copernicus, now seen as scientific heroes ${ }^{41}$. Thus the search for a criterion of demarcation risks falling into ahistoricity, and consequently losing its pejorative force. After all, if Newton was a pseudoscientist merely because the era into which he was born did not give him access to the tools necessary to refute doctrines of scriptural literalism, then being a pseudoscientist is hardly a culpable offense. In response, Kitcher proposes that "pseudoscience" be understood with reference to the persons who practice it, rather than the other way round. On this account, science and pseudoscience are differentiated by the psychology (and the consequent behaviour) of individuals. While the scientist is concerned with the adequacy of evidence and argument, the pseudoscientist (specifically, the creation scientist, in Kitcher's example) demonstrates "a kind of inflexibility, deafness, or blindness", repeating the same arguments ad nauseum regardless of the countervailing evidence raised by critical interlocutors ${ }^{42}$.

Therefore, for Kitcher, creationism is not the problem; it is "dead science" dragged back to the land of the living, and the problem lies with the values and motives of those who exhumed it, not the theory itself ${ }^{43}$. This is a plausible claim, which helps points the way to a criterion of demarcation that is sensitive to the contextual factors (such as the state of scientific knowledge in different eras of history) which determine what constitutes reasonable belief and practice. Unfortunately, the account is incomplete. The fact that a certain attitude underpins instances of pseudoscience is silent as to what causes that attitude to take root within certain groups, or

41 Philip Kitcher, Living with Darwin (New York: Oxford University Press, 2007), 26.

42 Ibid., The advancement of science: Science without legend, objectivity without illusions. (New York: Oxford University Press, 1993), 195.

43 Ibid., Living with Darwin, 12. 
among adherents to certain ideologies. Kitcher has a persuasive explanation as to why many devout Christians are reluctant to assent to scientific theories of evolution; they fear that to do so would undermine the veracity of the Bible, and thus the foundations of their faith ${ }^{44}$. However, this explanation is local to his case study. It is not obvious what the analogy in case of astrologers or anti-vaxxers might be, as it is not clear what comparable 'cost' abandoning one's views in these cases might have ${ }^{45}$.

\subsection{Pseudosciences as "degenerating” research programmes}

Imre Lakatos defends an account of pseudoscience derived from his view of the fundamental 'unit' of scientific practice. For Lakatos, this is not the theory, but the "research programme, a set of common assumptions and methods or "methodological rules" numerous theories might have in common. These fall into two categories: a "hard core" of relatively few rules that served to motivate the research programme, and a "protective belt of auxiliary hypotheses" 47 . Lakatos notes that no theory or research program is reconciled with every available piece of evidence; to be contradicted is mundane, as "all programmes grow in a permanent ocean of anomalies"48. Hence, the core is not typically questioned in the course of day-to-day scientific practice; the role of the belt is deflect, explain, or even absorb as evidence these apparently inconvenient facts in the core's defense. As all research programmes are thus companions in guilt in their struggle with recalcitrant evidence, Lakatos suggests that demarcation is to be found in the distinction between "progressive" and "degenerating" research:

44 Ibid., 42.

45 In fairness to Kitcher, his principal interest in this book is not the problem of demarcation, but the case of creationism itself.

46 Imre Lakatos, "Falsification and the methodology of scientific research programmes," in The Methodology of Scientific Research Programmes: Philosophical Papers Volume 1, eds. John Worral and Gregory Currie (New York, NY: Cambridge University Press, 1978), 47.

47 Ibid., 48.

48 Ibid., "Science and Pseudoscience," in The Methodology of Scientific Research Programmes: Philosophical Papers Volume 1, eds by John Worral and Gregory Currie (New York, NY: Cambridge University Press, 1978), 6. 
that which anticipates facts, and that which struggles to accommodate them ${ }^{49}$. Legitimately scientific protective belts do not 'shrink' research programs by adding auxiliary hypothesis that simply qualify and narrow their respective cores so as to avoid contradiction by evidence. Rather, in explaining existing evidence that contradictions the programme's core, these auxiliary hypotheses lead themselves to new discoveries. Lakatos gives the example of an astronomer who, upon finding that an object does not obey the orbital path that Newtonian mechanics predict, can then calculate the dimensions and trajectories of hypothetical objects which might have perturbed its orbit and then search for these $\mathrm{e}^{50}$. By contrast, in a degenerating or pseudoscientific research programme, the protective belt has ceased to or never did have these successes; it is taken up entirely in retroactively addressing other discoveries in order to remove contradictions between them and the core. Here, Lakatos' example (one of which Popper is also fond) is of 20th-century Marxism, which has been too preoccupied with attempts to resolve brute contradictions between historical materialism and recent history to make any new predictions in the $\operatorname{process}^{51}$.

\subsection{Pseudoscience as stagnation within a research community}

Paul Thagard proposes a dual criterion, which he illustrates against the example of astrology. He is convinced by Lakatos' critique of Popper, and sympathetic to the former's suggestion that demarcation is largely a matter of distinguishing progressive or productive theories from stagnant ones. Thagard suggests that the failure of previous attempts at demarcation can be understood with reference to what they have in common: their advocates'

49 Ibid., 5-6.

50 Ibid., "Falsification and the methodology of scientific research programmes," 17, 34.

51 Ibid., "Science and Pseudoscience," 6. 
preoccupation with showing that pseudoscience is theoretically or methodologically unsound ${ }^{52}$. However, astrology at its best has a decidedly science-like methodological structure: natural phenomenon (the relative locations of bodies in the sky) are observed, and used in turn to explicate other natural phenomenon (supposed patterns in events of human lives). Thagard's solution is to consider demarcation as involving questions about three facets of a possible pseudoscience: the theory itself (as Popper and others have done), but also the priorities demonstrated by its "community of practitioners" in working on the theory, and the theory's historical track record of contending with anomalous evidence and rival explanatory frameworks ${ }^{53}$. After considering astrology along these lines, Thagard proposes that a supposed science can be classed as pseudoscience if and only if

1) it has been less progressive than alternative theories over a long period of time, and faces many unsolved problems; but

2) the community of practitioners makes little attempt to develop the theory towards solutions of the problems, shows no concern for attempts to evaluate the theory in relation to others, and is selective in considering confirmations and disconfirmations ${ }^{54}$. Astrology fails this test because, while it may bear a methodological resemblance to science, it has barely changed in over 1800 years ${ }^{55}$. Practitioners have no response to evidence that the stars and planets manifest no properties which could plausibly influence the lives of individuals on Earth, given that objects must be either extremely large or relatively close for their "gravitational or radiative effects" to be measurable ${ }^{56}$. What really discredits them, in Thagard's view, is not 
this, but the fact that they have remained constant even as other theoretical frameworks (namely in psychology) have evolved to offer competing explanations for the patterns in human experience that astrologers are interested in. They have, so to speak, been left behind.

Progress-based efforts at demarcation leave difficult questions about the precise meaning of the notion of scientific 'progress'. If by 'progress' one means 'ability to change in response to challenges', as Thagard does, one risks admitting that some of the prime candidates for pseudosciences are sciences after all. As Kitcher shows, creationists have paid close attention to developments in the sciences. As evidence hostile to a young Earth (in terms of geology, and the sheer diversity of life) was amassed throughout the Scientific Revolution of the 17th and 18th centuries, they worked hard to counter it, producing tomes on where the waters of Noah's flood had retreated to and suggesting that the ark had merely had to accommodate animals of every genus or family, rather than species ${ }^{57}$. However, as this evidence became insurmountable, creationists realized (for the most part) that their ideas were untenable, mounting to the strategic retreat that led to today's "intelligent design" 58 .

To interpret progress as expansion of empirical content or enabling of further prediction, as Lakatos does, fares no better. His account implies that there is a natural life cycle to theories, whereby each starts as conjecture, is eventually elevated to productive mature science when its practitioners establish its "belt" to answer initial criticisms and refine the theory, and finally "degenerates" under the weight of unanswered fundamental challenges to its core, becoming a pseudoscience if not abandoned. This is certainly the case for some, and it is important to acknowledge (as Kitcher does with regard to creationism) that many pseudoscientific theories were entirely credible in a given historical context. However, this life cycle is not universal - if it

57 Kitcher, Living with Darwin, 25-31.

58 Ibid., 21. 
were, we would be forced to acknowledge that nothing had the status of "pseudoscience" from the day it was first practiced. Thus, Thagard's interpretation of progress will fail to condemn pseudosciences that demonstrate sufficient change, while Lakatos' simply fails to describe its object accurately.

2.4 Pseudoscience as syndrome

A.A. Derksen, writing in response to Laudan's criticisms of the continued effort at demarcation, describes the problem as a dilemma. On one hand, pseudoscience is sufficiently dangerous that demarcation is a worthy goal. One the other, science demonstrates considerable "heterogene[ity]" and imperfection with regard to its own ideals that the entire project risks simply reifying the prejudice, elitism, or conservatism of scientists ${ }^{59}$. Like Gordin, Derksen emphasizes the fact that as pseudoscience is fundamentally a form of mimicry, it should not be surprising that it is difficult to identify any universal characteristic to employ as criterion of demarcation. However, Derksen turns this mimicry, the "pretense" of pseudoscientists to scientific status, in his words, to his advantage ${ }^{60}$. While science may be fluid, changing considerably over time, by pseudoscientists' desire to be scientists they have committed themselves to the standards of contemporary science: namely, epistemic reliability, and the admission of human fallibility ${ }^{61}$. Thus, Derksen asserts, we have no need to identify any universal, ahistorical essence. All that is necessary is an "epistemic-social-psychological profile" of pseudoscience to map out how it fails to meet current scientific standards, consisting of seven characteristic "sins of pseudoscience" 62 .

59 Anthony A. Derksen, “The Seven Sins of Pseudo-Science," Journal for the General Philosophy of Science 24, no. 1 (1993): 19.

60 Ibid., 20.

61 Ibid., 19.

62 Respectively, "The Dearth of Decent Evidence", "Unfounded Immunizations” (of theory, from refutation by data), "The Ur-Temptation of Spectacular Coincidences" (or rather the refusal to acknowledge unlikely events as 
Notably, Derksen does not pretend that science is entirely free of the above. However, the scientist enjoys the advantage of "a critical tradition, which as a social institution guards against the seven sins of pseudo-science" ${ }^{93}$; their access to well-established and empirically supported theories, critically-minded collaborators, and (presumably) well-funded laboratories mean that the commission of these sins by genuine scientists will be hastily corrected, or occasionally justified.

These seven sins are not purported to be the substance of pseudoscience, but rather "forms in which the failure to have good reasons and the neglect of human fallibility present themselves" ${ }^{\prime 4}$. I do not disagree with Derksen on this point; in fact, the list of "warning signs" of pseudoscience presented in Chapter 4 echoes aspects of the seven sins. However, the price of Derksen's success is that his paper has scaled back the traditional ambitions of the demarcation project. He does not define pseudoscience, but shows how to recognize it, which is a poor substitute. Knowing what pseudoscience actually is in the abstract helps to predict where and when it is likely to arise, to craft strategies for countering it, and to diagnose marginal or "hard" cases. It does this because an actual definition implies the beginnings of a causal explanation of why incidents of pseudoscience tend, as Derksen argues, to produce problems with methodology and reasoning about evidence. No such explanation is to be found in a symptom-focused approach like Derksen's.

Furthermore, Derksen's resort to the "critical tradition" of a "social institution" to rescue science from its own examples of these sins is rapid and (ironically) uncritical. While no doubt

coincidences), "The Magic Method" (for the generation of whatever data are needed to corroborate the hypothesis), "The Insight of the Initiate" (i.e., "the claim that only the initiated person can really understand the theory"), "The All-Explaining Theory" (with which no data are incompatible) and "Uncritical and Excessive Pretension" (or selfaggrandization with regard to their work). Ibid., 21, 23, 26, 30, 32, 33, 36.

63 Ibid., 37.

64 Ibid., 37. 
welcome to those who identify with this social institution, this does not constitute a compelling argument for his conclusion that science is a trustworthy source of reliable knowledge. Therefore, those (such as policymakers) who are not experts in scientific methodology are not left with a way to distinguish genuine science that has lapsed into sin from actual pseudosciences that happen to have committed the same sin; in other words, who is and is not "inside" of this social institution remains an open question.

\subsection{Discussion}

Several important lessons can be learned from these authors' efforts to solve the demarcation problem. (1) It is important that our criterion satisfy basic intuitions about what pseudoscience (and science) looks like, and that it be at mostly commensurate with how the term is actually used outside of academic publications. This is why Gordin and Laudan's mutual observation that falsifiability cannot condemn as pseudoscientific claims that are ascertainably ludicrous; a criterion of demarcation which cannot identify a problem with classic examples of pseudoscience such as astrology and creationism is of no use at all. (2) As Lakatos, Thagard, and Kitcher all note, it is important that a criterion of demarcation be contextually sensitive, particularly with regard to history. The fact that "pseudoscience" in natural language is inherently a term of abuse implies that its failings are not innocent. Hence, when scientists go astray due to the inherent limitations within which they work (such as the inability of early evolutionary biologists to observe many generations of bacteria evolving under laboratory conditions, or their lack of access to gene theory), this should not suffice to condemn their work as pseudoscientific. (3) Given (2), and the more general reality that science itself is not static, it is worthwhile to work with Kitcher's postulate that the essence of pseudoscience lies with its practitioners, and not with their activities. Hence, this paper will proceed on the assumption that 
the problems with pseudoscience are attributable to the motives, values, or norms of pseudoscientists, reflected in "inflexibility, deafness, or blindness" toward evidence, as Kitcher suggests. (4) However, as the purpose of defining pseudoscience is to make it easier to recognize, it is important not to reduce it to a matter of pure psychology, given that the mental states of suspected pseudoscientists will typically be obscure. Therefore, I take up here Derksen's suggestion that science is differentiated from pseudoscience by the fact that it is practiced within a social institution which mitigates the harm done by individual failures of rationality. The 'attitudes' of (3) are thus to be seen as embodied in the values, purposes, and norms of a social institution, community, or subculture, rather than in single persons. (5) Finally, as noted toward the end of Chapter 1, this paper does not treat the search for a workable definition of pseudoscience as allied to the effort to demarcate science from all other practices or sources of knowledge.

\subsection{Conclusion}

My principal concern in this paper, as outlined in Chapter 1, is to identify a criterion of demarcation that can be used by policymakers and others in positions of influence over public management and governance to distinguish genuine scientific expertise from sophistry and deception. Chapter 2 has identified several features to be desired from a successful criterion of demarcation: it must be able to identify problems with the obvious pseudosciences, refrain from unfair condemnation of historic or imperfect science, clearly connect the application of the term "pseudoscience" to something undesirable, and be applicable to groups engaged in cooperative endeavours. With this review of the relevant literature, the old question "What is pseudoscience?" can now be parsed in an alternative (if less elegant) way that makes clear its import to contemporary social problems: "What characteristic of a community which develops 
theories and claims to knowledge which members identify as "scientific" render that community untrustworthy as a source of expertise?’. Hence, in the next chapter, I turn to Helen Longino’s writings on the possibility of objectivity in science. 


\section{Chapter 3}

The previous chapter concluded with a rough sketch of some of the features that we should expect (or demand) from a criterion of demarcation, on the assumption that we seek such a criterion with the intention of applying it. This is to say that the search is for a criterion that is not merely plausible insofar as it stands up to academic scrutiny ${ }^{65}$, but that can be used to help $d o$ things. Specifically, an applicable demarcation criterion will help do things essential to the practice of governance, such as decide whether or not an area of research is worthy of funding or can stand up as evidence in favour of some policy intervention. While I was not above (and shall not be here) exhaustive in my assessment of existing proposals, I believe that none quite meets the dual standards of accuracy and applicability. Here, I turn to Karl Popper's account of falsifiability as criterion of demarcation, to offer what is less an unqualified defense than it is a reinterpretation. While I acknowledge the force of the many criticisms this theory has attracted, I see in Popper's later works an insight ${ }^{66}$ that commentators have not recognized. This insight is that falsifiability can be understood as a social principle, a rule governing how institutions operate or how people interact with one another, and not only as a semantic feature of individual statements.

In what follows, I shall first explicate in greater detail the argument for falsifiability as a criterion of demarcation: as Popper is commonly read, as he writes in the early Logic of Scientific Discovery (LScD), and as he writes later in Conjectures and Refutations (CaR).

65 Nevertheless, this is an aim of this paper: my intention is to arrive at a definition of pseudoscience that is in fact correct, and not merely useful.

66 I do not mean to suggest that my reinterpretation is the "correct" reading of Popper's words in CaR. I think that it is more defensible than falsifiability as it is typically understood or articulated, but I do not know if Popper imagined himself to be revising his past work. Whether or not Popper's thinking evolved in the years between LScD and $\mathrm{CaR}$ (and, if so, whether he fully recognized this when writing) is historically interesting, and his correspondence and lecture notes from that period might shed light on the matter. However, this is outside the scope of this project. Hence, I remain agnostic with regard to any such "psychological" questions. 
Second, I shall lay out my alternate interpretation of $\mathrm{CaR}$, arguing that when understood as a social standard, falsifiability can escape many of the charges directed against it by critics such as Laudan and Gordin. Third, I draw upon this interpretation, in conjunction with Helen Longino's work on scientific objectivity, to inform my own proposed criterion of demarcation: the capacity of scientific communities of practice to subject theories to critical discussion, from which those theories that emerge intact gain credibility. Fourth, I will contrast my own proposed account with the list of criteria from the previous chapter, arguing that it reflects the best insights of existing literature, and is both conceptually plausible and pragmatically usable. Finally, I sketch briefly some of the ramifications of adopting my proposal. This would have the effect of driving the questions "what is science?" and "what is pseudoscience?" further apart than they have typically been construed to be, given that it typifies the latter as untrustworthy rather than as the antithesis of the former. This, in turn, is likely to collapse some traditional distinctions between pseudoscience on one hand and abused or manipulated science on the other, thus expanding the category of pseudoscience.

\subsection{The Conventional or "Semantic" Reading}

Popper's efforts at demarcation are typically understood as follows ${ }^{67}$ : Science deals exclusively with an external world, one shared among all observers, and makes about this world only those claims which can be falsified. Factual claims can, generally unproblematically, be divided into those which can be disproven, and those which cannot. The former class of statements are empirical, which is to say they concern observable matters of fact rather than

67 This paragraph is without citations or explicit reference to any particular author because I take this reading of Popper to be essentially a trope or caricature (although more accurate than these words may suggest). It is present in Laudan and Gordin's writings, and it least implicitly in those of other authors. It is the interpretation that will come to mind for most when "falsifiability" is invoked in a conversation among philosophers; it is a reading of the relevant texts that is considered common sense, that one need not defend as a legitimate interpretation. 
purely theoretical statements or value judgments. Take, for example, "all swans are white"; anybody can encounter a swan, and anybody who does so is likely to render the same judgment as to whether or not the swan is white. As soon as a black swan is encountered, this statement will be falsified. The latter class of statements, by contrast, are not empirical; they concern subjective matters, or perhaps unobservable aspects of the outside world. Examples of such statements include "I feel happy" and "No swan will ever be black".

Since science is concerned only with the former category, pseudosciences are those pretenders which fall short of the standard set by falsifiability. Freudians, for example, make claims that are "empirical" in the weak sense that they are about the outside world. However, there is no way to determine whether or not the events in so-and-so's love life that the Freudian attributes to an Oedipal complex are more than coincidental. Nothing that can be itself observed is uniquely compatible or incompatible with such an assertion, because the Freudian's theory does not "forbid" anything from happening ${ }^{68}$. Hence we cannot test the claim that Venus explains why so-and-so's love life has turned out the way it has. As the astrological theory cannot be falsified, it cannot be scientific: it is pseudoscientific.

There are many problems with falsifiability as it is articulated above; here, I shall briefly relate two of the most significant. As discussed in Chapter 2 above, Lakatos argues that "falsification", in the sense of "incompatibility with empirical evidence", is a permanent feature of the life of every scientific theory. Hence it cannot serve as a criterion of demarcation because it in no way separates "good" from "bad" theories. Perhaps even more damning is the fact that, as Thagard has noted, pseudosciences can be testable: his example, astrology, makes many claims that are susceptible to falsification, such as that persons born at a certain time of year

68 Karl Popper, Conjectures and Refutations (Abingdon-upon-Thames, UK: Routledge), 49. 
should demonstrate certain personality types ${ }^{69}$. These criticisms are forceful indeed, and against the conventional reading Popper, I take them to be decisive. However, I hold that the conventional reading is not the only one open to us. As I shall show below, a careful reading of Popper's two primary formulations of falsifiability, authored decades apart, supports the conclusion that they articulate substantively different positions ${ }^{70}$.

\subsubsection{The Logic of Scientific Discovery}

The account Popper presents in LScD is presumably the inspiration for the conventional reading's interpretation of the falsifiability (or non-falsifiabiality) of a candidate science as a pseudo-grammatical or semantic feature. However, some important nuances do tend to be lost in translation. As Popper writes, the process of testing begins with a "new idea"71. The extant literature on demarcation tends to write as though it is theories which are evaluated as falsifiable (or not), but in fact Popper is clear that hypotheses are also testable ${ }^{72}$. Similarly, "testing" is generally taken to mean "comparison with empirical evidence". While this is Popper's principal concern, he does also distinguish other types of test, such as non-empirical assessment of logical consistency between statements and comparison with competing theories ${ }^{73}$. Finally, Popper distinguishes between falsifiability, a property of statements or systems of such, and falsification, the event in which a statement or system actually is falsified. The former is determined simply by the existence of possible "singular statements of fact" incompatible with the postulate being tested $^{74}$. The latter, in contrast, occurs not simply when some datum allows a statement

69 Paul Thagard, "Why Astrology is a Pseudoscience", in Proceedings of the Biennial Meeting of the Philosophy of Science Association, (Chicago, IL: University of Chicago), 225-226.

70 By "leads to", I mean only that they can justifiably, or reasonably, be read as defenses of different positions. See footnote 2 above.

71 Popper, LScD, 32.

72 Ibid., 32.

73 Presumably in terms of simplicity, predictive power, and other such desiderata.

74 Ibid., 84. 
inconsistent with prediction to be made, but when a hypothesis predicting some recurring falsifying instance is supported by observation.

Despite such nuances, it is clear that $\mathrm{LScD}$ articulates something very close to the conventional reading. The text is replete with examples that support the interpretation of falsifiability as a semantic feature, none more decisive than the standard described above: it is the possibility of contravention by evidence that determines whether or not a statement is scientific. Consequently, LScD's gloss of falsificationism does not, according to the criteria I articulate in Chapter 2 above, constitute an adequate criterion of demarcation. In addition to its vulnerability to Laudan and Gordin's criticisms, it:

(1) distinguishes only between "science" and "nonscience", not "science" and "pseudoscience", thus failing to respect the intuition that it is inherently bad to be a pseudoscience, and

(2) is not, as a matter of logic, sensitive to social, historic, or cultural context nor

(3) easily applicable to values, attitudes, or behaviours, given that these are usually definition in contradistinction to logic while

(4) as any statement can be articulated by a lone agent, it does not respect that science is practiced primarily at the level of communities, rather than individuals

LScD has continued to shape the dominant understanding of Popper's work on demarcation. While it contains his lengthiest and most detailed account, it is not the last time he wrote on falsificationism.

\subsubsection{Conjectures and Refutations}

This later account hints at a different story. It presents Popper's view of pseudoscience as formulated through the transcript of a 1953 academic lecture. Admittedly, the text is intended to 
relate not only Popper's criterion of demarcation, but the biographical story of how he arrived at it. It is replete with anecdotes, and adopts a much less formal tone than LScD. Nonetheless, the most natural reading of this text points toward a criterion substantively different from that articulated in either the text of $\mathrm{LScD}$ or in the conventional reading. Even if one refrains from speculation about Popper's intentions, it is difficult to parse $\mathrm{CaR}$ as understanding falsifiability as a semantic property of theories in themselves as does LScD. Consider the following passages: Some genuinely testable theories, when found to be false, are still upheld by their admirers - for example by introducing ad hoc some auxiliary assumption, or by reinterpreting the theory ad hoc in such a way that it escapes refutation. Such a procedure is always possible, but it rescues the theory from refutation only at the price of destroying, or at least lowering, its scientific status. ${ }^{75}$ (emphasis mine) ...instead of accepting the refutations the followers of Marx re-interpreted both the theory and the evidence in order to make them agree. In this way they rescued the theory from refutation; but they did so at the price of adopting a device which made it irrefutable. ${ }^{76}$ (emphasis mine)

Here, we have examples in which the problems with the aspiring sciences in question cannot possibly be the type of statements through which they communicate findings, or for that matter any property of the candidate pseudoscience in its own right. Popper's admission that the pseudoscience itself may be "genuinely testable" is of considerable significance. It shows that here, the problem lies with what the Marxist (or other exponent of pseudoscience) has chosen to $d o$ in defense of their theory.

\subsection{Alternate/original reading}

75 Ibid., CaR, 48.

76 Ibid. 49. 
This, I propose, can motivate a tentative reinterpretation, and subsequently reevaluation, of Popper's doctrine. On this reinterpretation, a theory is pseudoscientific if, and only if

(1) It claims, tacitly or explicitly, to be scientific ${ }^{77}$

(2) Its proponents conduct themselves in such a way so as to make refutation of the theory impossible; the defenses they raise could plausibly be invoked against any criticism or piece of evidence that might jeopardize the theory ${ }^{78}$.

Call this the "attitudinal" reading of Popper, in contrast with the traditional "semantic" reading. It focuses, as Kitcher recommends, on the persons who advocate a theory, rather than on the substantive content of the theory itself. Thus any system of statements can be pseudoscientific, should those who argue for them behave in a sufficiently discreditable manner when defending them. I do not mean to assert or even imply that this is Popper's "real" view. More modestly, I want to suggest that, were someone to encounter Popper's later work for the first time, without prior impressions framed by the conventional reading, this is just as intuitive an interpretation as any other, and that it does not subvert Popper's own goals.

The reinterpretation can answer many criticisms that traditional interpretations cannot. It incorporates Kitcher's suggestion that the focus should be on the pseudoscientists themselves; thus, there is no danger that will oblige us to condemn historical scientific theories on the basis that they have been subsequently discredited (unless, that is, some fringe element continues to defend them long past the point where this is reasonable). It is no longer a problem that many pseudoscientists make claims that are theoretically susceptible to empirical refutation. AIDS

77 I take this to be implicit in Popper's demarcation, and in most.

78 As Lakatos notes, all research programs are circled by a "belt" of what might be called rescue hypotheses, intended to answer criticisms, explain inconvenient data, and so on. It is, of course, important to distinguish legitimate responses to criticism that "amend" theories from evasiveness or deflection of the kind Popper's Marxist engages in. I am persuaded by Popper's solution to this problem, which is to "bar" amendments which decrease the net empirical content of the theory; i.e., they widen, rather than qualify, the range of potential phenomenon with which it is compatible (cite). 
denialists and their ilk can still be condemned for their refusal to take the evidence that counts against their position seriously. Moreover, the attitudinal reading provides an answer to Gordin's suggestion that demarcation is inherently futile, given that the very nature of pseudoscience is to adapt and mimic whatever makes science distinctive: such mimicry is precisely the sort of refutation-subverting evasiveness that this criterion condemns.

However, there are still outstanding difficulties for this revised version of falsifiability. First, even if the attitudinal account is theoretically convincing, it is not clear precisely what is to be its object of assessment. A criterion of demarcation is of no use if it cannot be used, and the cost of switching from a semantic strategy is that it is much more difficult to determine whether a person and their character are permissive of falsification (and what characteristics are relevant to this) than it is a sentence. Second, apart from this problem of implementation, there remains a theoretical difficulty: neither Popper's writings nor my reinterpretation give us any reason to believe that scientists are any better on this front. Sophisticated methodologies, well-equipped laboratories, and prolonged educations do not give any reason to think that scientists are necessarily more open to criticism than pseudoscientists.

\subsection{Longino on Scientific Objectivity}

So is there any reason to believe that science is especially conducive to Popper's cherished critical discourse? I submit that there are. Helen Longino, writing in response to claims that science was so infected by the human values and biases of its practitioners as to render it hopelessly subjective, argues that counterintuitively, it is precisely the social nature of science that put objectivity within reach ${ }^{79}$. This echoes Derksen's brief (and unsubstantiated) assertion, discussed in Chapter 2, that it is the norms and rules of the "social institution" of science, such as

79 Helen Longino, Science as Social Knowledge: Values and Objectivity in Scientific Inquiry (Princeton, NJ: Princeton University Press). See 3, 9-12. 
peer review, that secure the work of flawed scientists from falling prey to the same transgressions that pseudoscientists do. However, unlike Derksen, Longino puts flesh to these bones.

Her concern is to reconcile what she sees as the inevitable influence of human values ${ }^{80}$ on science with its place of esteem in contemporary society, as an objective mode of inquiry. Longino holds that this is entirely possible, so long as "objectivity" is understood as "assess[ment of] hypotheses and theories in an unbiased and unprejudiced manner" ${ }^{81}$. On this interpretation, objectivity consists neither in the absence of influence by values, nor in the impossibility of disagreement not motivated by ignorance or dishonesty ${ }^{82}$. It obtains instead when the influence of values is acknowledged, without any allowed to dominate so that science is a mere reflection of one set of norms or interests. Longino argues that this ideal can be realized because science is a social endeavour, requiring the shared efforts of numerous individuals ${ }^{83}$. This is true of the practice of science, which is interdependent in the sense that any practitioner will rely on their fellows for education, ideas, material resources, and so on. It is also part of the character of scientific knowledge, which is a status attained by research findings only once they become accepted by fellow scientists and incorporated into study designs, literature reviews, and so on ${ }^{84}$.

In addition to its social nature, science is a "public" affair, with its outputs able to be shared $^{85}$. This is true in two important senses. First, science is often funded at least partially by

80 "Value" is to be understood in the broadest possible sense, to include ethical norms, conceptions of the good life, objects of desire, ideological considerations, and so on.

81 Ibid., 63.

82 Contrast with the Aristotelian ideal of science described by Laudan, as discussed in Chapter 1.

83 Ibid., 67.

84 Note that this is independent of whether a scientific claim or finding is actually true: knowledge, unlike truth, is at least partly a matter of psychology.

85 Ibid., 69-70. 
taxation, leading to a norm of considering it to be a public good, and to the fact that scientific findings are often shared freely in the media rather than guarded as intellectual property. Second, science is conceptually public. It investigates the properties of an external world that is mutually experienced. Consequently, scientific findings are "intersubjectively ascertainable" 86 ; at least in principle, anybody could acquire the requisite expertise to observe or experience whatever scientific findings anybody else does. In conjunction with its sociality, the publicity of science is what lends it naturally to criticism. The most important of the many forms of criticism, Longino holds, involves the articulation and scrutiny of the "assumptions in light of which the data are interpreted", or the "background beliefs" of researchers ${ }^{87}$. As this is one of the primary routes through which the values held be scientists may enter their work, it is essential to objectivity that they not be beyond criticism.

But what facts about the scientific communities which actually exist make them conducive to this sort of criticism? Longino identifies four general features. The first, "Recognized avenues for criticism", is the observation that there are certain arenas designated for the sharing of new ideas, most notably peer review and conference presentations ${ }^{88}$. Regardless of scientists' desire to participate in these "avenues", it is difficult to secure intellectual influence or career advancement without doing so. Moreover, these arenas facilitate two-way communication: fellow scientists and students can participate in peer review and pose questions at conferences. Second, Longino notes that science is generally marked by "shared standards" 89 . In order to persuade one another of the veracity or applicability of findings, scientists must appeal to a

86 Ibid., 70.

87 Ibid., 72-73. Take, for example, the belief held by some biologists that to "explain" an organism's trait is, by definition, to identify its historical function. This background belief will influence what sort of hypotheses are posed by introducing presumptions such as that there is or was such a function.

88 Ibid., 76.

89 Ibid., 77. 
common language about constitutes good science; consider the near-universal belief that for one theory to subsume two represents an advance. This common conception of the good enables scientists to offer criticisms of which their audience are apt to feel the force. Third, science exhibits "community response": evidence exists that received wisdom does change over time, often in response to criticism ${ }^{90}$. Longino suggests that the contents of textbooks and the trends in granting can serve as helpful barometers for this. Finally, science generally succeeds in maintaining approximate "equality of intellectual authority" $"$. Ideas are not generally judged on the basis of their authors, or the identity of the interests they serve $\mathrm{e}^{92}$; it is conceivable for a mere graduate student to publish work critical of research by much more established researchers.

Taken together, these features of science suggest a field in which it is exceptionally difficult to avoid criticism. The social interdependence of practice oblige scientists to interact with and rely on their fellows. This provides ample informal opportunities for critique, whether during debate over methodology in the laboratory or over coffee. Meanwhile, as for scholars the currency of career success is one's ability to share ideas (measured through publications and citations), scientists have a strong interest in participation in activities that lay their ideas, methodological details, assumptions, scholarly rationale, and all, exposed to the slings and arrows of their compatriots. In turn, these compatriots have an incentive to engage in critique, providing as it does opportunities for recognition or new research questions. Consequently, the belief that the authority afforded science is merited by default need not rely on the assumption that scientists are all especially scrupulous, or bear a noble and detached fascination with truth. It

90 Ibid., 78.

91 Ibid. Notably, Longino believes that this is the metric on which mainstream science in the developed world scores most poorly, given the extent that conservative ideological commitments with regard to sex and race have been reflected in scientific research.

92 This is, of course, an ideal not always entirely realized. 
needs only the assumption that practicing scientists are placed within social institutions that levy expectations and incentivize behaviour in a way that happens to be conducive to genuine engagement with ideas.

\subsection{Revised falsificationism}

Popper's work details how science, as an endeavour which seeks to produce knowledge about the world, is critique-apt. Criticism is not destructive, but progressive, insofar as it can serve to refine or replace flawed theories with superior alternatives. Longino's writings are, I submit, thematically similar and naturally complementary. She illustrates how science is practiced in contexts which make it probable that the criticism Popper describes will actually come to pass. Therefore, I propose uniting the reinterpretation of Popper's falsificationism in 3.2 above with Longino's insight: that scientific objectivity is conferred by the social context within which science is practiced. The resulting revisionist version of falsificationism can be presented as follows:

A hypothesis, theory, knowledge claim, concept, or any other output of scientific practice is pseudoscientific if and only if

- Its proponents claim, explicitly or otherwise, that it is genuine science, and thus has earned the credibility associated with science, but

- The community in question is marked by norms which render it unable to subject its intellectual output to meaningful criticism, meaning that

- Whatever faults the "scientific" output may have, be they incompatibility with evidence or the preference for speculative, unobserved entities (such as an omnipotent Creator) over more prosaic explanatory devices, will not generate an adequate response within the community 
To put this more concisely, pseudoscience is simply whatever emerges from a community that cannot or will not scrutinize its members' ideas before accepting them. This revisionist account differs in several important regards from Popper's canonical proposals. Nevertheless, I hold that CaR's suggestion, by way of the Marxist anecdote related in 3.1.3, that a theory could collapse into pseudoscience as a result of the conduct sanctioned among its proponents, means that my proposal is very much true to the spirit of his work. These differences are, I hold, chiefly advantageous, as they answer the four criticisms of Popper articulated in 3.1.2.

First, unlike falsificationism in its original form, the revised version distinguishes science from pseudoscience without collapsing the distinction into that between science and nonscience. Instead, it is science gone wrong. Second, and perhaps most significantly, revised falsificationism substitutes "Will it be criticized?" in place of "Can it be criticized?". The object of direct assessment is the setting from which a theory originates, not the theory itself. Consequently, falsificationism becomes context-sensitive rather than logic-oriented: there is no concern that this criterion of demarcation will exclude genuine science from years past, such as the early creationist proposals discussed by Kitcher. Third, the shift from logic to context allows norms, values, and behaviours to play a role, making it much easier to explain how Popper's Marxist has rendered his theory unfalsifiable. Fourth, by shifting the object of assessment from statements to social contexts, revised falsificationism reflects the empirical fact that science is generally a shared activity. To find a lone crank pseudoscientist among a lab of serious researchers would be strange indeed.

\subsection{Some Implications}

First, as Longino notes, all four of these features can obtain of a community to a greater or lesser degree. This is decidedly unlike the standard employed by the semantic reading of 
falsificationism; either a statement can conflict with observations, or it cannot. Consequently, it is inevitable that the use of these four criteria to assess a community's capacity to subject science to critical discourse will leave some hard, marginal cases, where reasonable disagreement remains as to whether or not objective discourse is possible.

Second, while one of my goals in this paper is to arrive at a criterion of demarcation that is compatible with our powerful (and largely uniform) intuitions about the paradigmatic examples of pseudoscience, it is implausible to expect that the choice of demarcation criterion will not affect in some way what is or is not categorized as pseudoscience. As I have stressed repeatedly, under my proposal, pseudoscience is not a methodological or procedural flaw, a matter of incompetence in the performance of basic science. Consequently, there are likely to be cases where the discourse around technically proficient research is so distorted by the influence of power or money as to become pseudoscience (see Longino's requirement for "equality of intellectual authority", above). Consider, as potential examples, industry-funded research which purports to show that cigarettes are not a cause of lung cancer, or that the climate crisis is unrelated to human activity. Pseudoscience manifests in the 'soft landing' of ideas without due diligence and scrutiny, not in the procedures by which these ideas are initially generated.

A third consequence of adopting this criterion is the relegation of motives to something very near irrelevance, so far as the identification of pseudoscience is concerned. As Gordin suggests, part of the received common-sense about pseudoscientists is that they think of themselves as scientists. I agree with this, and hence it can be expected that they are united in their desire to earn the respect that scientists enjoy. At a high level of generality, all pseudoscientists are motivated by the desire to be taken as authorities in their respective fields. What they wish to $d o$ with this authority is a question beyond the scope of this paper to answer. I 
can only postulate that there is as much variation here as with possible uses to which authority can be put.

Fourth, the shift to a standard based on features of communities negates much of the need for concern with the conduct or attitudes of individuals. So long as "equality of intellectual authority" is approximated, whether any one scientist is willing to take criticism seriously is of little consequence, as individuals lack the power to single-handedly elevate conjecture to purported truth. Even if one does intransigently continue to defend a theory that has been clearly falsified, the refusal of community members to overlook its faults can prevent it from taking on an air of supposed respectability.

\subsection{Conclusion}

In this chapter, I have sketched out a comprehensive reimagining of Karl Popper's work on the demarcation problem. My contention here is that interpreting the "falsifiability" of scientific research as something determined by the standards of discourse and cooperation within the community of practitioners, rather than as a property of scientific outputs in their own right. Hence, this proposal substitutes social norms, such as the expectation that one will consider themselves accountable to critics and submit their work to certain forms of scrutiny, for the semantic or logical elements of Popper's theory. The "badness" of pseudoscience thus consists in the misappropriation of science's epistemic authority. As Longino shows, this authority is due science in light of its nature as a social activity with public products: as a genuine scientist, it is difficult to avoid criticism by one's fellows. Hence, while the pronouncements of scientists are not necessarily more likely to be true than those of others, they do enjoy a special sense of trustworthiness. Science might have its flaws, but these are soon laid bare for all to see. 
This concludes the theoretical contribution of the present paper. However, I have yet to show that my work has practical applicability: that the proposed criterion of demarcation can actually be used to distinguish concrete cases of pseudoscience. As Chapter 1 above illustrates, pseudoscience does not pose a problem merely for scholars, but for policymakers who must be able to identify genuine scientific expertise in order to carry out the mandates of various organizations within the broader public sector. Therefore, in the following chapter, I aim to show that the revised falsificationist account can be a useful tool for public servants by aiding in the identification of pseudoscience. 


\section{Chapter 4}

In the previous chapter, I proposed a revised form of Karl Popper's falsificationism as a criterion to demarcate science from pseudoscience. On this suggestion, a theory, practice, factual claim, or program of research is pseudoscientific if it is claimed to be scientific, but its chief proponents work within a social context absent the feature which makes the predicate "scientific" a badge of honour: conduciveness to robust critical discussion which would expose flaws in the supposed science. Here, I aim to show that this proposal has practical and not merely theoretical import by laying out how it can be operationalized. To this end, I apply revised falsificationism to a case study: the disgraced former gastroentorology researcher Andrew Wakefield's notorious studies of children with autism spectrum disorders (ASD). Wakefield claims to have demonstrated that these disorders are symptoms of a gastrointestinal autoimmune disease caused in turn by the measles, mumps, and rubella vaccine (MMR), a position which mainstream medical researchers find untenable.

I identify in this case study several indications that little if any critical discourse is possible among Wakefield, his supporters, and his collaborators. Namely, Wakefield (1) aims to disseminate ideas through popular rather than expert channels, (2) treats his qualifications as a sort of personal virtue, (3) presents his expertise as unbounded by subject matter, and (4) operates within an incentive structure that presents rational motives for unscrupulous behaviour. I interpret these indications not as mere idiosyncracies of the Wakefield case, but general symptoms of pseudoscience ${ }^{93}$. Finally, I conclude the chapter with a brief discussion of how

93 My use of "symptoms" here is intended to contrast with "signs"; I suggest that these are not merely indications that something is pseudoscientific, but that they are also why we should be concerned that something is pseudoscientific. 
scientists and policymakers might promote a public image of scientific authority as something inherently conditional and finite, a form less conducive to abuse.

\subsection{Wakefield}

An academic researcher specializing in pediatric gastroentorology, employed by London's Royal Free Hospital, Andrew Wakefield rose to prominence as the lead author of an infamous 1998 scholarly publication. "Ileal-lymphoid-nodular hyperplasia, non-specific colitis, and pervasive developmental disorder in children," 94 published in the prestigious medical journal The Lancet. The paper concerned research conducted into 12 children reported to have autism spectrum disorders (ASD), finding that eight had developed their symptoms between one and fourteen days of receiving the measles, mumps, and rubella (MMR) vaccine ${ }^{95}$. In conjunction with a press conference Wakefield held to announce this finding, publication of the paper touched off a firestorm of alarm in the press, and was followed by a decline in vaccination rates in the United Kingdom ${ }^{96}$. About a week later, he (and others, largely separate from his authorship group) submitted a business proposal to the Royal Free Hospital, proposing a joint venture that would offer commercial diagnosis and treatment services for patients of "autistic enterocolitis" while developing "safe vaccines", as Wakefield held that the problem was particular to the three-in-one MMR vaccine ${ }^{97}$. The next year, he and a similar group of investors were awarded public funds to found another private diagnostics firm in Ireland.

These dramatic findings were not without their critics. Approximately a year and a half after the Lancet published Wakefield's findings, Royal Free and its affiliated medical school

94 Henceforth simply "the Lancet paper/publication".

95 Brian Deer, "How the Case against the MMR Vaccine Was Fixed," British Medical Journal 342, $\quad$ no. 7788 (2011): 78.

96 Ibid.,"How the Vaccine Crisis Was Meant to Make Money.” British Medical Journal 342, no. 7789 (2011): 138. 97 Ibid., 140. 
hired a new head of medicine, Mark Pepys, at whose instigation the institution raised concerns with Wakefield's commercial plans. The latter was informed that the dependence of a significant financial stake upon evidence that "[did] not conform to...rigorous academic and scientific standards" raised the spectre of conflict of interes ${ }^{98}$. Consequently, Wakefield was offered institutional and financial backing for a larger-scale study to replicate the prior findings of the Lancet paper. He agreed, but after nearly two years without progress (or any indication that the research was under way), he was dismissed with severance pay. In Pepys' words, "We paid him to go away," thus marking the last time to date Wakefield held office in a recognized institution of health or science ${ }^{99}$.

Two years later, the controversy attracted the attention of the investigative journalist Brian Deer, whose reporting into the affair triggered an investigation by the United Kingdom's General Medical Council ${ }^{100}$ (GMC) into the ethical rectitude of the original mid-1990s research upon which the Lancet paper was based. This afforded Deer the opportunity to contrast patient records with Wakefield's published findings. Together with interviews with the parents of several children who had been involved, these comparisons revealed the study to have been fraudulent, the data extensively manipulated ${ }^{101}$. Among other instances of misconduct, several of the children who the publication had reported were "normal" prior to receiving the MMR vaccine had already exhibited signs of 'abnormal' development. A full three quarters of the children had also undergone tests for inflammation of the colon, which were initially recorded as

98 Ibid., 141.

99 Ibid., 142.

100 Responsible for professional licensing of medical practitioners.

101 Ibid., "How the Case against the MMR Vaccine Was Fixed," 78. 
negative, but subsequently changed after "research review" to findings of "non-specific colitis"102.

Moreover, it became apparent that throughout the study, Wakefield had been on the payroll of a lawyer. Richard Barr represented an advocacy organization that alleged vaccination had injured its members' children and intended to sue for damages; he would eventually pay Wakefield the equivalent of nearly a million Canadian dollars ${ }^{103}$. Additionally, Wakefield had been filing patents and legal aid grant applications citing an established connection between MMR and ASD not merely before publication, but before data collection had even begun ${ }^{104}$. As a result of these investigations, most of Wakefield's co-authors retracted support for the Lancet paper's conclusions in 2004. In 2010, the journal retracted the paper in its entirety, and a few months later, Wakefield and one of his co-authors were deemed ineligible to practice by the GMC. It cited many ethical lapses, some beyond the falsification of data and failure to disclose conflicts of interest - such as collecting blood samples for his research from children attending his child's party, without prior ethics approval ${ }^{105}$.

Around the time when Deer began his investigation, Wakefield left the United Kingdom for Austin, Texas. Though no longer employed in academia or mainstream health care, there is ample demand for him to speak at public talks and rallies. He is working on his second book about the supposed failure of mainstream medicine to reckon with the issues that concern him, and has directed a documentary about the supposed conspiracy to conceal the connection between vaccines and autism. His many followers, generally members of what might charitably

102 Ibid.

103 Ibid., 77.

104 Ibid., "How the Vaccine Crisis Was Meant to Make Money," 138.

105 Susan Dominus, "The Crash and Burn of an Autism Guru.” New York Times, April 20, 2011, https://www.nytimes.com/2011/04/24/magazine/mag-24Autism-t.html. 
be called "vaccine-skeptical" parents' groups, are adoring, some openly tearing up or using literally messianic terms when they speak of him $^{106}$.

\subsection{Manifestations of pseudoscience}

Wakefield is not a pseudoscientist simply because his study made factually inaccurate claims. There is no need for any concept other than "factual inaccuracy" to make sense of this. Similarly, it is not the fact that the Lancet study was dependent upon falsified data: this is already subsumed within the broader concept of scientific misconduct or fraud. This is, I hold, an illuminating case in part because it serves to sharpen the conceptual distinction between fraud and pseudoscience. Initially, as a scientist in good standing who engaged in forbidden conduct for personal gain, Wakefield was a fraud. Only later, after his expulsion from the world of academia and subsequent reinvention of himself as a self-styled speaker of truth to power, did he become a pseudoscientist. In other words, Wakefield's career shows a clear break from one community, with norms and practices conducive to the production of objective knowledge, and entrance into another, which lacks any such thing. Furthermore, his deeds illustrate one of my central contentions. Pseudoscience is not merely a surreal and comic world of cheap hucksters, outspoken paranoiacs, and UFO religions. It is a clear and present danger; Wakefield's promotion of his falsified results resulted in the waste of considerable public resources. In conjunction with his allegations of a conspiracy to silence him, they have very likely caused deaths via the mechanism of vaccine hesitancy ${ }^{107}$. I submit that the following features of the Wakefield case justify the inference that his work takes place within a context that fails to

106 Ibid.

107 See the return of measles, as discussed in Chapter 1. During the long investigations into Wakefield's misconduct, the United Kingdom saw its first measles death in 14 years; see Deer, "How the Vaccine Crisis Was Meant to Make Money", 139. 
encourage critical discussion, and hence that they show advocacy of his theories on autism to be pseudoscientific.

(1) Wakefield disseminates his ideas through popular rather than expert channels. He publishes through the non-academic press, and speaks at rallies, rather than conferences. The chief problem with this is not that it allows Wakefield to avoid the 'quality control' aspects of peer review and conference acceptance. Rather, it is that avoidance of these "recognized avenues for criticism", as Longino describes them, reduces the chance that his audience will be exposed to any contravening ideas. At rallies and talks organized by anti-vaccine activists, there is not likely to be anyone in attendance with formal educational credentials, a command of past scholarly findings, or familiarity with health-sciences jargon on par with Wakefield's. Thus this also serves to diminish the "equality of intellectual authority" within the community.

(2) Freed from the bounds of academia, Wakefield has treated his qualifications as a sort of personal virtue. No clear explanation is given as to why he is both willing and able to perceive truths that are apparently beyond the reach of nearly all other researchers. He presents his expertise as unbounded by subject matter; his former credentials were in gastroenterology, and he has little or no formal training in the recognition of signs of autism. It is perhaps telling that the Lancet study originally required the contributions of a dozen co-authors ${ }^{108}$. Nonetheless, Wakefield operates as though his expertise is singular, exemplified by one follower's claim that they see him as "Nelson Mandela and Jesus Christ rolled up into one" 109.

(3) The above is especially problematic in light of the fact that Wakefield now operates within an incentive structure that presents rational motives for unscrupulous behaviour. He is dependent on the continued loyalty and admiration of his followers for financial backing. The

108 Ibid., 138.

109 Dominus, "The Crash and Burn of an Autism Guru." 
more dramatic his indictments of a malicious "medical establishment", the more attention and loyalty he can command. Engagement with other scholars and their ideas is no longer a route to career advancement, and hence retreating from positions now comes at considerable cost. (4) Wakefield frequently alleges that his critics share nefarious motives, conspiring actively and maliciously to discredit his ideas. While it is, in a literal sense, a response, it is a refusal to engage with critiques as ideas. This represents a total lack of "responsiveness" to criticism, as well as a refusal to acknowledge the validity of a communal set of shared "standards" to which everyone's research might be held.

In sum, what these manifestations of pseudoscience add up to is the assertion that one enjoys the credibility that is due a prophet, rather than a scientist. His separation from the broader community of scientists means that one who encounters his ideas through the venues in which they are promulgated has no assurance that they have been challenged forcefully, revised appropriately, and thus earned their place. Without the critical discourse ensured by the norms and values of the scientific community, there is nothing to guarantee that Wakefield's claims constitute even an effort to arrive at truth other than his own scruples - scruples which, given the manner of his exile, one has good reason to doubt. A statement like "the MMR vaccine causes the onset of autism" is clearly a falsifiable statement, and thus scientific by the lights of traditional interpretations of Popper. The purpose of revising falsification is to substitute for "can it be falsified?" a more useful question. When one with a fiscal stake in maintaining others' faith operates without any meaningful intra-communal challenge to their authority, can there be any rational expectation that their doctrines will be falsified, should the need arise? The answer, I hope to have shown, is a resounding "no". Policymakers, lay citizens, and anyone else looking 
for a source of expertise should beware self-styled prophets, who can give no assurances save their own excellence.

\subsection{Recommendations}

In this and the preceding chapters, I have laid out of view of pseudoscience as the appropriation and subsequent abuse of epistemic authority: the credibility that contemporary society tends to assign to those speaking on behalf of science. This is both a conceptual analysis, in that it strives to account for what the essence of pseudoscience actually is, and a normative claim, insofar as I hold the account to give a sufficient explanation of why pseudoscience is considered to merit disapproval. It would be an interdisciplinary undertaking far beyond the scope of this paper to outline a comprehensive strategy to counter pseudoscience, "fake news", and other prevalent dubious knowledge claims, likely drawing primarily upon empirical psychology. However, I do hold that one strategy follows directly from conceptualizing pseudoscience in this way: a reimagining of scientific authority, making science more accessible to the public and portraying the expertise of scientists in more qualified terms.

Recent polling in the United States has found that $86 \%$ of Americans express trust in scientists when considering "their competence, credibility and commitment to the public"110. This far exceeds the levels of confidence expressed in politicians, the news media, religious leaders, or business, and moderately exceeds that expressed in the military, demonstrating that the issue is not a lack of regard for science. To the contrary, it is the inability to reliably discern what is science. To remedy this, scientists should be encouraged to increase the lay public's exposure to science by disseminating ideas in the public sphere as well as the academic.

110 Cary Funk, Meg Hefferon, Brian Kennedy, and Courtney Johnson, “Trust and Mistrust in Americans' Views of Scientific Experts," Pew Research Center, August 2 2019, https://www.pewresearch.org/science/2019/08/02/trustand-mistrust-in-americans-views-of-scientific-experts/. 
Outreach of this kind can be conducted by giving talks open to all, ideally in off-campus spaces such as libraries, participation in public meetings and consultations where their expertise is relevant, and submission of commentary-style short written pieces to newspapers and nonspecialist websites. Academic institutions can encourage these activities by considering evidence of commitment to public education when making hiring or promotion decisions, by making space on campus available for scientific outreach, and by including the dissemination of knowledge throughout society as a whole in their mission statements. In turn, governments can use their funding levers to encourage research into science education, and to mandate universities to assist their faculties' efforts toward these ends.

It would be naive to suppose that the average citizen will attain a deep knowledge of any scientific field after attending a few lectures. Instead, my proposal is intended to help facilitate recognition of scientific expertise. In essence, the aim is to empower citizens to distinguish the type of authority with which scientists speak from that which pseudoscientists claim to: not to be able to judge all of the facts themselves, but to know when one should or should not place trust in another's claim to expertise. Isabel Smith and Noni MacDonald, in their guidelines for resisting the denial of scientific evidence relating to ASD, stress that the priority is to "inoculate" those likely to be exposed to misinformation, rather than to win arguments with denialists or pseudoscientists themselves ${ }^{111}$. While Smith and MacDonald's focus is on the tailoring of responses to specific rhetorical tropes often deployed in the context of autism, much of their advice is applicable to other scientific communication in the general public sphere. They present a scenario in which a hypothetical scientist, confronted with advocacy for some other "expert's" financially-motivated hoax remedy for ASD, takes (among others) the following steps:

111 Isabel Smith and Noni E. MacDonald, "Countering Evidence Denial and the Promotion of Pseudoscience in Autism Spectrum Disorder," Autism Research 10, no. 8 (2017): 2-3. 
1) Conceding authority and qualifying own expertise: The scientist does not claim to be an expert in the domain of the hoax remedy, reiterating that they are an authority with regard to ASD, but not all matters of psychological development or health care. Consequently, they do not assert that the hoax remedy is without merit in all circumstances, but only that it is not shown to be useful in the treatment of ASD. By stressing the narrowness of their own expertise, thus demonstrating humility, the scientist appears more credible when arguing that the hoax remedy's proponents lack authority in the field of ASD.

2) Qualifying expectations: The scientist speaks in negatives ("has not been shown"), qualifies claims when necessary, and avoids making statements about "proof". Consequently, they present the degree of certainty with which science operates in a more realistic light. This helps to show that the scientist insists on treating their own findings skeptically, just as they do the findings of others.

3) Emphasizing consensus: The scientist avoids speaking in personal terms or appealing only to what they personally know. Instead, they emphasize the role of others in conducting studies which bolster their claim that the hoax remedy is not supported by evidence. This shows that in holding themselves positioned to speak as an expert, the scientist is not claiming personal virtue or exceptionalism, but a condition in which they rely on their colleagues.

Thus imagined, scientific authority is easily distinguished from the prophetic authority of the pseudoscientist. My suggestion is to 1) give the lay public more opportunities to encounter genuine science presented in an accessible format and 2) within this arena, temper the rhetoric with which knowledge is presented, so as to make clear the contingent and interdependent nature of "truth" in science. The aim of this intervention is, at heart, a simple one: to heighten the contrast between science and pseudoscience. The intention is to show the average citizen that the 
scientists in which they already tend to place their trust have earned their position not through savantry or a suprasensible privileged access to the truth, but through hard work, a skeptical mindset, and the ability to rely on others.

\subsection{Summary}

In this chapter, I have applied the revised falsificationist account of pseudoscience, as developed in Chapter 3 above, to a case study. The Wakefield affair represents an egregious breach of scientific norms, and so it might reasonably be asked why we need to bother with lengthy conceptual analysis when this is so clearly evident. I contend that this exercise is worthwhile because there is no reason to believe that the emergence of another Wakefield is impossible. It took over a decade after the Lancet paper was published for it to be retracted and the author to lose his credentials, giving him several years to spread anti-vaccine myths while able to truthfully call himself a doctor with an accomplished curriculum vitae. It is clear that there are still lessons that need to be learned from the textbook examples of pseudoscience, so as to lessen the vulnerability of society to the teachings of the next generation of false prophets. To this end, the case study demonstrates the explanatory power of revised falsificationism: when applied to the Wakefield affair, it is able to satisfy the intuition that this represents something qualitatively different and quantitatively more dangerous than mundane fraud or incompetence. 


\section{Conclusion}

In this paper, I have pursued two goals. The first was to illustrate two interlinked problems presented by pseudoscience. While there is remarkable agreement among informed persons as status of examples like astrology as pseudosciences, others are able to masquerade as science with more success, owing to the credentials and past achievements of exponents like the rogue AIDS denialist Peter Duesberg. Given the success of pseudoscientists in commanding significant audiences, their interest in influencing public life becomes a concern to policymakers, whose work often depends upon access to reliable scientific expertise. This practical problem is accentuated by the fact that the extant scholarly literature has met with limited success in defining pseudoscience. There is no consensus as to what pseudoscience actually is. While a wide range of "criteria of demarcation" have been proposed as ways to identify impostor science, each has significant faults.

My second goal was to propose a solution to the problem of demarcation, in hopes that this could find application to the practical problems posed for policymakers by pseudoscience. To this end, I have suggested a reinterpretation of Karl Popper's doctrine of falsificationism. According to Popper, genuine scientific theories can be 'falsified'. This is to say that their predictions, or other statements whose truth would follow from that of the theory, can be expressed in terms capable of clashing with empirical observations. Hence science is progressive, insofar as the falsifiability of theories makes them apt to constructive criticism. Scientific knowledge can thus be improved over time as theories are falsified, and either modified or abandoned. Pseudoscience, by contrast, is expressed in terms that are too vague or abstract to contradict evidence. It cannot be falsified, and hence lacks the progressive character of science. 
My proposal is that Popper's falsificationism can be augmented with Helen Longino's understanding of scientific objectivity, as a property achieved due to the social character of scientific inquiry. It would be impracticable for one to practice science without depending on others, and impossible for one's findings to attain the status of "knowledge" without convincing others of their import. Therefore, its practice exposes candidate theories and findings to potential criticism from colleagues and stakeholders whose beliefs and interests are diverse. Science is thus objective, insofar as the biases and incentives of individuals are likely to be neutralized or "cancelled out". On my revised account, the falsifiability of a theory is determined not by the semantic form of its expression, as in Popper's work, but by the nature of the community from which it emerges. Pseudoscience thus becomes the output of "scientific" research communities incapable of subjecting ideas to robust criticism, allowing them to emerge into the wider world without proper scrutiny.

Thus, the distinction is one of credibility. Science is practiced in contexts where ideas are quite literally exposed to criticism, through their airing before skeptically minded audiences at conferences, after submission to journals, and in review of funding applications. Thus, whether or not an observer is well-versed in a particular academic field or not, they can make a reasonable assumption that what is upheld as scientific knowledge represents more than the expression of the narrow ideological or material interests of its exponents. Pseudoscience, by contrast, is conceived of and disseminated within communities that, due to inequalities of power, ideological homogeneity, or incentives for dishonesty, cannot be assumed to subject ideas to any meaningful scrutiny. This strength of this approach to the demarcation problem, as demonstrated in the last chapter, is the ease of its application. In order to distinguish science from pseudoscience, citizens and policymakers alike need not become scientific experts in their own 
right. They need only to recognize the signs of a community within which criticism is perfunctory. 


\section{References}

Adhopia, Vik. "Why is $\$ 350000$ in Canadian Aid Being Used to Send Homeopaths to Honduras?” CBC News, February 23, 2019. https://www.cbc.ca/news/health/ federal-aid-homeopaths-honduras-1.5030384.

BBC World News. "SA’s Zuma 'Showered to Avoid AIDS'.” April 5, 2006.

http://news.bbc.co.uk/2/hi/africa/4879822.stm

Dabbagh, Alya., Rebecca L. Laws, Claudia Steulet, Laure Dumolard, Mick N. Mulders, Katrina

Kretsinger, James P. Alexander, Paul A. Rota, and James A. Goodson. "Progress towards

Regional Measles Elimination: Worldwide, 2000-2017.” $\quad$ Morbidity and Mortality Weekly

Report 67, no. 47 (2018): 1323-1329. DOI: http://dx.doi.org/10.15585/mmwr.mm6747a6

Deer, Brian. "How the Case against the MMR Vaccine Was Fixed. British Medical

Journal 342, no. 7788 (2011): 77-82.

. "How the Vaccine Crisis Was Meant to Make Money." British Medical

Journal 342, no. 7789 (2011): 136-142.

Dominus, Susan. "The Crash and Burn of an Autism Guru.” New York Times, April 20, 2011.

https://www.nytimes.com/2011/04/24/magazine/mag-24Autism-t.html.

Chapman University. "Survey of American Fears 2018: Paranormal.” Last modified October 16, 2018. Retrieved from https://blogs.chapman.edu/wilkinson/2018/10/16/paranormalamerica-2018/

Cousins, Sophie. "Measles: A Global Resurgence.” The Lancet Infectious Diseases 19, no. 4 (2019): 362-363. https://doi.org/10.1016/S1473-3099(19)30129-X

Gewirtz, Paul. “On 'I know it when I see it'.” The Yale Law Journal 105, no. 4 (1996): 10231047. 
Gordin, Michael D.. The Pseudo-Science Wars: Immanuel Velikosvky and the Birth of the Modern Fringe. Chicago, IL: University of Chicago Press, 2013.

International Life Sciences Institute. “Mission \& Operating Principles”. Accessed July 132019. https://ilsi.org/about/mission/.

Kalichman, Seth C. Denying AIDS: Conspiracy Theories, Pseudoscience, and Human Tragedy. New York, NY: Springer, 2009.

Kata, Anna. "Anti-vaccine activists, Web 2.0, and the postmodern paradigm: An overview of tactics and tropes used online by the anti-vaccination movement." Vaccine 30, no. 25 (2012): 3778-3789. doi:10.1016/j.vaccine.2011.11.112

Kitcher, Philip. The Advancement of Science: Science without Legend, Objectivity without Illusions. New York, NY: Oxford University Press, 1993. . Living with Darwin: Evolution, Design, and the Future of Faith. New York, NY: Oxford University Press, 2007.

Kumar, Sanjay. “In India, Hindu Pride Boosts Pseudoscience.” Science 363, no. 6428 (2019): 679-680. DOI: $10.1126 /$ science.363.6428.679

Lakatos, Imre. "Falsification and the Methodology of Scientific Research Programmes." In The Methodology of Scientific Research Programmes: Philosophical Papers Volume 1, edited by John Worral and Gregory Currie, 8-101. New York, NY: Cambridge University Press, 1978. . "Science and Pseudoscience." In The Methodology of Scientific Research Programmes: Philosophical Papers Volume 1, edited by John Worral and Gregory Currie, 1-7. New York, NY: Cambridge University Press, 1978.

Laudan, Larry. Beyond positivism and relativism. Boulder, CO: Westview Press, 1994. 
Longino, Helen. Science as Social Knowledge. Princeton, NJ: Princeton University Press, 1990.

Popper, Karl R. The logic of scientific discovery. New York, NY: Harper \& Row, 1959. . Conjectures and refutations. Abingdon, UK: Routledge, 2002.

Public Policy Polling. "Republicans and Democrats differ on conspiracy theory beliefs."Accessed May 26, 2019. Retrieved from https://www.publicpolicypolling. com/wp-content/uploads/2017/09/PPP_Release_National_ConspiracyTheories_ 040213.pdf

Steel, Sarah, Gary Ruskin, Lejla Sarcevic, Martin McKee, \& David Stuckler. “Are IndustryFunded Charities Promoting “Advocacy-Led Studies” or "Evidence-Based Studies”?: A Case Study of the International Life Sciences Institute." Globalization and Health 15, no. 36 (2019): 1-8. https://doi.org/10.1186/s12992-019-0478-6

Sturt, Jackie, Saima Ali, Wendy Robertson, David Metcalfe, Amy Grove, Claire Bourne and Chris Bridle. "Neurolinguistic Programming: A Systematic Review of the Effects on Health Outcomes.” British Journal of General Practice 62, no. 604 (2012): 757-764. DOI: 10.3399/bjgp12X658287.

Thagard, Paul. "Why astrology is a pseudoscience" In Proceedings of the Biennial Meeting of the Philosophy of Science Association, 223-234. Chicago, IL: University of Chicago, 2004. 